The comet is increasing in brightness, and is moving in a south-easterly direction through Aries and Taurus. On the 17 th it passes close to the Pleiades, and on the 3 oth it is close to $\alpha$ Tauri (Aldebaran). A telegram from Herr Wolf, of Heidelberg, states that the comet is about the II th magnitude (Ast. Nach., Bd. 148 , No. 3552 ).

Meteor Observations from a Balloon.-The March number of the Bull. de la Soc. Astr. de France contains an article by M. A. Hansky, of the Meudon Observatory, describing his attempt to observe the Leonid meteor shower in November 1898 from a balloon. The experiment was so far successful in that the observers saw a number of meteors, the sky to them being perfectly clear, although to the people on terra firma in Paris the sky was completely clouded over. This was at a height of only about I50 metres. Attention is also drawn to the other astronomical observations which might be made in this way when otherwise impossible on account of local weather conditions. Among these may be mentioned the observation of solar and lunar eclipses, the zodiacal light, the gegenschein, and aurore, which last are probably very frequent but masked by atmospheric glare or insufficient transparency of the air at low levels.

The first balloon ascent for astronomical purposes, so far as is known, was made by the Russian chemist Prof. Mendeléef, who, by this means, was enabled to observe the total eclipse of the sun in 1867 .

Planetary Perturbations. - In Ast. Nach., Bd. I48, No. 3549 , Prof. S. Newcomb draws attention to a source of error in the formulæ used in computing the positions of the planets at future or past epochs. In the method of "special perturbations," which is often used, a small error in the decimal places, arising from superfluous numbers or uncertainty in the data is, from the nature of the integrals, accumulative with the time. Prof. Newcomb takes integrals of the various types commonly used, and shows the relative errors introduced in their evaluation. The mean longitude, requiring two integrations for its determination, will have a more rapidly accumulating error than the other elements, and hence its computation should be done with special care.

U.S. Naval Observatory. - IVe have just received the report of the superintendent of the Naval Observatory for the fiscal year ending June 30 , I898, embodying the several reports made by the directors of the various departments.

The 26-inch refractor has almost exclusively been used on faint and difficult objects, including observations of D'Arrest's and Giacobini's comets; measures of Titan and Japetus for a new determination of the mass of Saturn ( $\mathrm{I}: 349 \mathrm{r} \cdot 8$ ), this appearing to be affected by the different brightness of the two, so new measures of Rhea and Japetus are to be made; forty-one complete measures of position angle and distance of Neptune's satellite were obtained, and the diameters of Mercury and Venus on all possible occasions.

Some interesting experiments were made to spectroscopically determine the colour curve of the 26 -inch. The minimum focal length occurs about $E$, from which the focal plane for $F$ is 0.142 inches, and for $G$ (iron) I 233 inches distant.

The r2-inch has been used in observing comets, minor planets, occultation of stars, and eclipses of Jupiter's satellites. In past years this instrument has been used for the exhibition of celestial objects to the public on two evenings each week this has now been limited to one evening. The number of visitors during the year has been nearly 1500

Two new instruments have been acquired, a 6-inch transit circle and a 5 -inch altazimuth, both marking a new departure in being made entirely of steel, in the endeavour to reduce to minimum the changes due to flexure and temperature. Both instruments have been made by an American firm, this choice being seemingly justified by their performance after installation.

The new tables of the planets Mars, Uranus and Neptune are nearly completed ready for publication.

The department of nautical instruments, chronometers and watches was under a great strain during the war with Spain all available instruments in the country being purchased, and many having to be sent out without the complete tests usually applied before acceptance.

The magnetic department is likely to be abandoned owing to the serious disturbing effects of the currents leaking from the numerous electric plants in the immediate vicinity.

\section{ALLOYS OF IRON AND NICKEL.}

$A^{T}$ the Institution of Civil Engineers, on March 28, a paper A was read on "Alloys of Iron and Nickel," by Mr. R. A. Hadfield. The effect upon iron of gradually increasing amounts of certain added foreign elements has already been investigated by Mr. Hadfield in experiments upon the mechanical and physical properties of alloys of iron and manganese, silicon, aluminium and chromium, both in the cast and forged conditions. The present paper contains the results of a similar investigation of the alloys of iron and nickel. The addition of nickel, either by conferring greater homogeneity or by some particular combination with the iron or carbon present, or both, appears to confer properties upon the alloy equivalent to an annealing, or, if annealing be employed, to reduce the stress produced by forging; it does this even in the annealed material without injuring or seriously lowering the elastic limit. In this respect, therefore, its presence is of considerable practical utility. It would appear there is considerable room for improv. ing the material of propeller-shafts. The well-known Russian metallurgist, Chernoff, has stated that steel is composed of crystals of metallic iron cemented by carbide of iron, the result being that in the case of nickel-iron alloys the intercrystalline spaces (a subject which has been fully and carefully investigated by Mr. T. Andrews, F.R.S., as regards ordinary steel) are much more completely filled, and the cohesion consequently rendered more powerful. The points of solidification of the cement and crystals are nearer, thus producing or maintaining a more intimate interweaving of the elements. In support of this theory may be cited the fact that without doubt nickel-iron alloys show less tendency to segregation, which apparently indicates that the combinations formed at high temperature are more intimately maintained when the alloy cools and becomes solidified than is the case with ordinary steel. That scientific evolution disregards nationalities is well illustrated in the case of the metal nickel and its developments. The Swedish chemist Cronstedt, at work in his laboratory, conceived the idea that the deceptive Kupfer-Nickel is a metal containing a new element; from him it passed to other Swedish investigators, thence to those of German, French, and other nationalities. Attempts were made by Faraday to artificially produce meteoric iron; similar efforts were afterwards made in France, Germany and elsewhere. Apparently a period of inactivity followed, during which, however, first one and then another experimenter added facts to the general stock. Finally, as regards the metallurgy of nickel as applied to iron and steel, Marbeau, in France, applied the matter experimentally; Schneider, in France, perfected its application to a number of purposes, chiefly armour-plates; Riley brought the manufacture to a practical issue in England; American and Canadian enterprise followed in the perfecting of cheaper methods of producing nickel, and a new product-nickel steel -appeared. It has taken about 125 years to arrive at the stage reached to-das. No one person, no one nationality, can lay claim to its discovery, to its inception. If a chart were constructed on genealogical lines, how much wnuld be seen to have sprung from the laboratory experiments by Cronstedt? But, if it were possible, long before the work of the Swede would be discovered the early workers of the old world in China and Japan, about whose work dates and facts were inaccessible. Apparently, to modern ideas, mention of nickel appears to have struggled into existence between the years 1600 and 1700 , but the metal must have been well known, not merely centuries, but almost thousands of years earlier.

\section{THE PRESENT STATE OF EVOLUTION. ${ }^{1}$}

NLY a little less than fifty years have passed since the pub. lication of Darwin's "Origin of Species," and the general acceptance by naturalists of the theory of descent. Since 1848 the sciences of embryology, cytology, and comparative anatomy based on embryology - or, as it is now called, morphology-have been placed on a firm foundation. It is but little over half a century since the uniformitarian views of Lyell were promulgated. The cell doctrine was born in 1839 ; the view that pro1 Prologue of an address entitled "A Half-Century of Evolution, with
special reference to the Effect of Geological Changes on Animal Life," delivered by Prof. Alpheus S. Packard before the Section of Zoology of the American Association for the Advarcement of Science at the Boston meeting (fiftieth anniversary) on August 22, 1898 . 